\title{
OTIMIZAÇÃo DAS CONDIÇõeS DE PRODUÇÃo DE ÉSTERES ETÍlICOS A PARTIR DE ÓLEO DE PEIXE COM ELEVADO TEOR DE ÁCIDOS GRAXOS $\omega$-3
}

\author{
Juliana Maria Leite Nóbrega de Moura*, Lireny Aparecida Guaraldo Gonçalves, Renato Grimaldi, Marinalda da Silva \\ Soares e Ana Paula Badan Ribeiro \\ Departamento de Tecnologia de Alimentos, Faculdade de Engenharia de Alimentos, Universidade Estadual de Campinas, CP \\ 6091, 13081-970 Campinas - SP, Brasil
}

Recebido em 12/7/05; aceito em 16/12/05; publicado na web em 6/7/06

\begin{abstract}
OPTIMIZATION OF THE PRODUCTION CONDITIONS OF ETHYL ESTERES FROM FISH OIL WITH HIGH CONTENT OF IN $\omega$-3 LONG CHAIN FATTY ACIDS. The production of ethyl esters by alcoholysis is an alternative for splitting triacylglycerols due to the possibility of using low temperatures, which results in oxidative protection of the polyunsaturated fatty acids. Ethyl esters produced under mild conditions of temperature could be used as substrate for obtaining structured lipids. The reaction parameters of production of ethyl esters from fish oil with high content of $\omega$ - 3 fatty acids by alcoholysis were optimized using response surface methodology. An experimental design ( $2^{3}$ ) (with levels +1 and -1 , six axial points with levels $-\alpha$ and $+\alpha$ and three central points) was applied. The variables investigated were concentration of catalyst, amount of ethyl alcohol and temperature. Ethyl ester conversion was monitored by high performance size exclusion chromatography (HPSEC) and the best result obtained was $95 \%$ conversion rate. The optimal conditions were $40{ }^{\circ} \mathrm{C}, 1 \%$ of $\mathrm{NaOH}$ and $36 \%$ of ethanol.
\end{abstract}

Keywords: ethyl esters; alcoholysis; high performance size exclusion chromatography.

\section{INTRODUÇÃO}

Os óleos provenientes de peixes marinhos contêm grandes quantidades de ácidos graxos poliinsaturados de cadeia longa $\omega-3$, que são oriundos do ácido graxo linolênico advindo das plantas utilizadas na alimentação dos peixes. Sua composição específica em ácidos graxos $\omega$-3 justifica a grande utilização em nutrição humana. Os principais ácidos graxos desta classe são o eicosapentaenóico (EPA) e docosaexaenóico (DHA), podendo representar cerca de $26 \%$ dos ácidos graxos presentes em óleos de peixe. A utilização de ácidos graxos da série $\omega$-3 apresenta grande influência no metabolismo dos triacilgliceróis, nos níveis de colesterol LDL, além da interferência na agregação plaquetária reduzindo o risco de doenças cardiovasculares $^{1,2}$.

Os óleos e as gorduras têm a sua aplicação industrial limitada pela distribuição e composição em ácidos graxos, sendo necessário submetê-los a processos de modificação, tais como hidrogenação, interesterificação e fracionamento, para que as características físico-químicas sejam alteradas ${ }^{3,4}$.

O processo de interesterificação pode ser dividido em quatro classes de reações: alcoólise, acidólise, glicerólise e transesterificação. A alcoólise, reação entre uma gordura e um álcool, oferece meios de preparação de ésteres como alternativa ao processo de hidrólise e reesterificação. Os ésteres são obtidos pelo deslocamento do glicerol pelo álcool, que pode ser metílico ou etílico, na presença de catalisadores, produzindo metil ou etil ésteres ${ }^{5}$ :

$$
\mathrm{C}_{3} \mathrm{H}_{5}(\mathrm{OOCR})_{3}+3 \mathrm{CH}_{3} \mathrm{CH}_{2} \mathrm{OH} \longrightarrow
$$

O processo convencional de obtenção de ácidos graxos utiliza temperaturas elevadas, na faixa de $150-280{ }^{\circ} \mathrm{C}$, onde a temperatura

*e-mail: jumanobrega@yahoo.com.br escolhida determina maior ou menor tempo de reação, podendo levar à oxidação de óleos poliinsaturados ${ }^{5}$, como o óleo de peixe.

Os ésteres etílicos têm surgido como um substrato alternativo para a obtenção de lipídios estruturados específicos, devido à possibilidade de utilização de baixas temperaturas no processo, o que permite proteger os ácidos graxos poliinsaturados da oxidação.

O objetivo do presente trabalho foi otimizar as condições de produção de ésteres etílicos a partir de óleo de peixe, com elevado teor de ácidos graxos $\omega-3$, através do processo de alcoólise em escala piloto, visando sua utilização como substrato para a reação de produção de lipídios estruturados específicos.

\section{PARTE EXPERIMENTAL}

\section{Óleo de peixe}

Para a produção dos ésteres etílicos foi utilizado como matériaprima óleo de peixe com elevado teor de ácidos graxos $\omega$-3 (ROPUFA - Roche), gentilmente cedido pela empresa Parmalat.

\section{Caracterização da matéria-prima}

- Teor de ácidos graxos livres - método AOCS Ca 5a-406;

- Composição em ácidos graxos - método AOCS Ce 1-62 6 , Condições da análise: Cromatógrafo CGC Agilent 6850 GC System. Coluna DB - 23 - Agilent (50\% Cianopropil - metilpolisiloxano), $60 \mathrm{~m}$ x 0,25 mm x 0,20 $\mu \mathrm{m}$. Forno: $195{ }^{\circ} \mathrm{C}-20 \mathrm{~min} ; 195-215^{\circ} \mathrm{C} \mathrm{a}$ $5{ }^{\circ} \mathrm{C} / \mathrm{min} ; 215^{\circ} \mathrm{C}-16 \mathrm{~min}$. Gás de arraste: He; fluxo da coluna $1,0 \mathrm{~mL} / \mathrm{min}$; injetor $-250{ }^{\circ} \mathrm{C}$; detector $-280{ }^{\circ} \mathrm{C}$; split $-1: 50$. A identificação dos ácidos graxos foi realizada através da comparação dos tempos de retenção das amostras e do padrão cromatográfico NU-CHEK GLC-87;

- Metilação - método AOCS Ce $2-66^{6}$;

- Índice de Peróxido - método AOCS Cd 8b-906;

- Índice de Anisidina - método AOCS Cd 18 - $90^{6}$. 


\section{Reação de alcoólise}

A reação de alcoólise foi realizada em reator de $3 \mathrm{~L}$, encamisado e provido de agitação mecânica. Para os testes preliminares foram utilizados $2 \mathrm{~kg}$ de óleo de peixe, soluções de $\mathrm{NaOH}$ em álcool etílico anidro com concentrações de 1,0,1,13 e 1,20\% e 40 partes de álcool etílico anidro. A reação ocorreu sob agitação de $600 \mathrm{rpm}$, durante 5 min e a $60{ }^{\circ} \mathrm{C}$. Para os ensaios experimentais utilizou-se um sistema em batelada com lotes de $0,6 \mathrm{~kg}$ de óleo de peixe, que foi aquecido a diferentes temperaturas. Para cada experimento foi adicionada solução de $\mathrm{NaOH}$ em álcool etílico anidro, de acordo com concentrações descritas no planejamento experimental. A reação ocorreu sob agitação mecânica de aproximadamente $600 \mathrm{rpm}$, durante 5 min. Após o término da reação, adicionou-se glicerol em quantidade suficiente para acelerar a separação do glicerol produzido e, após a decantação do mesmo, foi realizada sua remoção, sendo os ésteres submetidos a diversas lavagens com água pré-aquecida, até que estivessem límpidos e neutros. No mesmo reator foi realizada a secagem à vácuo dos ésteres, à $60^{\circ} \mathrm{C}$.

\section{Planejamento experimental}

Para a obtenção das melhores condições operacionais para a produção de ésteres etílicos de óleo de peixe foi aplicado um modelo fatorial completo $\left(2^{3}\right)$, com os níveis de +1 e -1 , seis pontos axiais $(-\alpha e+\alpha)$, três pontos centrais (nível zero), em que as variáveis estudadas foram concentração do catalisador, quantidade de álcool etílico e temperatura. O planejamento constou de 17 experimentos, sendo três no ponto central e seis nos pontos axiais. Os valores das variáveis foram selecionados em função de testes preliminares (Tabela 1). O tempo de reação e a velocidade de agitação foram de 5 min e $600 \mathrm{rpm}$, respectivamente. Os resultados foram avaliados através da aplicação de MSR - Metodologia de Superfície de Resposta e Análise de Regressão Múltipla?.

Tabela 1. Níveis e variáveis avaliados no planejamento experimental

\begin{tabular}{lccccc}
\hline & \multicolumn{5}{c}{ Níveis } \\
Variáveis & $-\alpha$ & -1 & 0 & +1 & $+\alpha$ \\
\hline Temperatura $\left({ }^{\circ} \mathrm{C}\right)-\mathrm{X}_{1}$ & 39 & 45 & 52,5 & 60 & 65,20 \\
$\mathrm{NaOH}(\%)-\mathrm{X}_{2}$ & 0,93 & 1,0 & 1,1 & 1,2 & 1,27 \\
Etanol $(\mathrm{v} / \mathrm{p})-\mathrm{X}_{3}$ & 26,53 & 30 & 35 & 40 & 43,47 \\
\hline
\end{tabular}

A resposta ao delineamento foi dada em função da avaliação quantitativa do rendimento em ésteres, determinado através da técnica de cromatografia de alta performance por exclusão de tamanho.

\section{Controle da reação}

A reação de obtenção dos ésteres foi monitorada através da técnica de cromatografia de alta performance por exclusão de tamanho (HPSEC) nas seguintes condições: duas colunas conectadas em série, Hewlett Packard - DVB (Polidivinilbenzeno), com diâmetros de poros de 100 e $500 \AA ̊$; detector de índice de refração (Differential Refractometer LCD 201 - Sicon - Analytic); bomba isocrática (PerkinElmer, série 10 - Liquid Chromatograph), injetor de $20 \mu \mathrm{L}$ e fluxo de fase móvel (Tetraidrofurano) de $1 \mathrm{~mL} / \mathrm{min}^{8}$.

O mecanismo de separação dos ésteres, através da técnica HPSEC, ocorre através da diferença de massa molar entre os compostos presentes no meio reacional, sendo que, neste caso, a ordem de eluição é triacilgliceróis, diacilgliceróis, monoacilgliceróis, ésteres e ácidos graxos livres.

\section{RESULTADOS E DISCUSSÃO}

A eficiência da reação de conversão de triacilgliceróis em ésteres depende diretamente das condições de processo utilizadas, bem como das características físico-químicas da matéria-prima. Dentre as variáveis que afetam a reação de alcoólise temos o teor de ácidos graxos livres, umidade, tipo de catalisador e concentração utilizada, razão molar de álcool/óleo e tipo de álcool utilizado, tempo de reação, temperatura, agitação e pureza dos reagentes ${ }^{9}$.

\section{Caracterização da matéria-prima}

A composição em ácidos graxos do óleo de peixe utilizado como matéria-prima para a produção de ésteres é apresentada na Tabela 2.

Tabela 2. Composição em ácidos graxos do óleo de peixe

\begin{tabular}{llr}
\hline & Ácidos Graxos & \multicolumn{1}{c}{$\%$} \\
\hline C12:0 & Láurico & 0,31 \\
C14:0 & Mirístico & 7,06 \\
C15:0 & Pentadecanóico & 0,59 \\
C16:0 & Palmítico & 17,98 \\
C16:1 & Palmitoléico & 7,55 \\
C17:0 & Margárico & 0,90 \\
C17:1 & Margaroléico & 1,04 \\
C18:0 & Esteárico & 5,25 \\
C18:1 & Oléico & 13,53 \\
C18:2 & Linoléico & 2,37 \\
C18:3 & Linolênico & 1,13 \\
C18:4 & Estearidônico & 3,37 \\
C20:0 & Araquídico & 0,46 \\
C20:1 & Gadoléico & 1,31 \\
C20:3 & Eicosatrienóico & 0,87 \\
C20:4 & Araquidônico & 0,77 \\
C20:5 & Eicosapentaenóico (EPA) & 14,80 \\
C22:0 & Beênico & 0,63 \\
C22:5 & Docosapentaenóico (DPA) & 1,92 \\
C22:6 & DHA & 18,15 \\
& Total (EPA + DPA + DHA) & 34,87 \\
& Total n-3 PUFA & 36,30 \\
\hline
\end{tabular}

As características físico-químicas do óleo utilizado na reação de alcoólise, tais como teor de ácidos graxos livres, índice de peróxido e umidade, apresentam grande influência na eficiência da reação, podendo reagir com o catalisador, diminuindo assim a eficiência da conversão de triacilgliceróis em ésteres. Quanto maior a acidez do óleo, menor a eficiência da conversão. Para a obtenção de maior eficiência na conversão, o óleo utilizado deve apresentar teores de ácidos graxos livres, índice de peróxido e umidade máximos de $0,1 \%, 10$ meq $\mathrm{O}_{2} / \mathrm{kg}$ e $0,1 \%$, respectivamente ${ }^{10}$.

$\mathrm{O}$ óleo utilizado como matéria-prima na reação de alcoólise apresentou excelentes características em termos de acidez (\% AGL em oléico $=0,1$ ) e baixíssimos valores de índices de peróxido (meq $\mathrm{O}_{2} / \mathrm{kg}$ óleo $\left.=0,1\right)$ e de anisidina $(0,3)$, indicando bom estado oxidativo.

A partir dos resultados dos testes preliminares foi elaborado um planejamento experimental onde as variáveis independentes (temperatura, concentração de $\mathrm{NaOH}$ e etanol) foram avaliadas dentro de uma faixa específica (Tabela 1). De acordo com este planejamento, o número total de combinações de tratamento foi $2 \mathrm{k}+2 \mathrm{k}+\mathrm{n}$, onde $\mathrm{k}$ é o número de variáveis independentes e n é o número de repetições dos experimentos no ponto central. 


\section{Otimização dos parâmetros reacionais}

A Tabela 3 apresenta o planejamento experimental para a otimização das variáveis avaliadas $\left(\mathrm{X}_{1}\right.$-temperatura, $\mathrm{X}_{2}$-concentração de $\mathrm{NAOH}, \mathrm{X}_{3}$-etanol anidro) para a produção de ésteres etílicos e os resultados de conversão em ésteres.

Tabela 3. Planejamento experimental para otimização das variáveis avaliadas para a produção de ésteres etílicos de óleo de peixe

\begin{tabular}{lcccc}
\hline Experimentos & $\mathrm{X}_{1}$ & $\mathrm{X}_{2}$ & $\mathrm{X}_{3}$ & $\begin{array}{c}\text { Rendimento } \\
\text { em ésteres } \\
(\%)\end{array}$ \\
\hline 1 & $\left(\right.$ Temperatura $\left.{ }^{\circ} \mathrm{C}\right)$ & $(\mathrm{NaOH} \%)$ & $($ Etanol v/p) & 95,08 \\
2 & $1(60)$ & $1(1,2)$ & $1(40)$ & 93,95 \\
3 & $-1(45)$ & $1(1,2)$ & $1(40)$ & 92,64 \\
4 & $1(60)$ & $-1(1)$ & $1(40)$ & 93,89 \\
5 & $-1(45)$ & $-1(1)$ & $1(40)$ & 86,71 \\
6 & $1(60)$ & $1(1,2)$ & $-1(30)$ & 90,01 \\
7 & $-1(45)$ & $1(1,2)$ & $-1(30)$ & 89,36 \\
8 & $1(60)$ & $-1(1)$ & $-1(30)$ & 85,83 \\
9 & $-1(45)$ & $-1(1)$ & $-1(30)$ & 92,83 \\
10 & $0(52,5)$ & $0(1,1)$ & $0(35)$ & 91,42 \\
11 & $0(52,5)$ & $0(1,1)$ & $0(35)$ & 92,01 \\
12 & $0(52,5)$ & $0(1,1)$ & $0(35)$ & 89,97 \\
13 & $1,68(65,20)$ & $0(1,1)$ & $0(35)$ & 89,81 \\
14 & $-1,68(39,8)$ & $0(1,1)$ & $0(35)$ & 82,18 \\
15 & $0(52,5)$ & $1,68(1,27)$ & $0(35)$ & $9(35)$ \\
16 & $0((52,5)$ & $-1,68(0,93)$ & $0(35)$ & 84,96 \\
17 & $0(52,5)$ & $0(1,1)$ & $1,68(43,47)$ & 94,96 \\
\hline
\end{tabular}

A técnica HPSEC permitiu a separação dos diferentes compostos de acordo com sua massa molar. A Figura 1 apresenta um exemplo de perfil cromatográfico em que se verifica a conversão de triacilgliceróis em ésteres do experimento $\mathrm{n}^{\circ} 17$ do planejamento experimental. Através do perfil cromatográfico obtido verifica-se a presença de $15 \%$ de triacilgliceróis (TG), 12,7\% de diacilgliceróis (DG) e $72 \%$ de ésteres etílicos de ácidos graxos de cadeia longa (EEAGCL), mostrando a eluição dos compostos em função da sua massa molar.

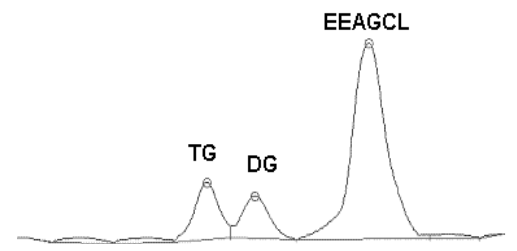

Figura 1. Perfil cromatográfico para avaliação do rendimento dos ésteres, ondeTG = triacilgliceróis, $D G=$ diacilgliceróis e EEAGCL = ésteres etílicos de ácidos graxos de cadeia longa

Em testes preliminares realizados para a obtenção de ésteres etílicos de óleo de peixe obteve-se uma taxa de conversão de $100 \%$ para a concentração de 1,20\% de hidróxido de sódio e 40 partes de álcool etílico anidro (Tabela 4).

No entanto, verifica-se nos ensaios experimentais uma taxa máxima de conversão em ésteres de $95 \%$. Os testes preliminares e os ensaios experimentais foram realizados no mesmo reator, com mesma matéria-prima e agitação, tendo como fonte de variação no processo a quantidade da matéria-prima utilizada, 2 e $0,6 \mathrm{~kg}$, respecti-
Tabela 4. Condições preliminares utilizadas na produção de ésteres

\begin{tabular}{cc}
\hline$\% \mathrm{NaOH}$ & Rendimento em ésteres $(\%)$ \\
\hline 1,0 & 95,6 \\
1,13 & 98,0 \\
1,20 & 100,0
\end{tabular}

Temperatura $=60^{\circ} \mathrm{C}$ e Volume de etanol $=40$ partes

vamente. A agitação do processo é parâmetro importante para se chegar à melhor eficiência de conversão em ésteres. $\mathrm{O}$ reator utilizado foi desenhado com pás de agitação para volumes da ordem de 3 L. Quando se diminuiu a massa inicial de amostras para 0,6 kg, parte da hélice de agitação deixou de estar totalmente submersa no óleo, o que pode ter alterado a excelente condição de agitação encontrada nos testes preliminares, reduzindo assim a taxa de conversão em ésteres.

A equação de regressão de segunda ordem mostra a dependência da conversão de óleo em ésteres etílicos como função da quantidade de etanol utilizada na reação. Os parâmetros da equação foram obtidos pela análise de regressão múltipla dos dados do experimento:

$$
Y=92,05296+4,53679 X_{3}-2,37387 X_{3}^{2}
$$

onde Y é a variável dependente, rendimento em ésteres, em relação a variável independente $X_{3}$ - etanol. As variáveis $X_{1}$ - temperatura e $\mathrm{X}_{2}$ - concentração de $\mathrm{NaOH}$ não apresentaram efeitos estatisticamente significativos.

Através da análise de variância (ANOVA) determinou-se o valor de $\mathrm{F}$, que é a razão da média quadrática devido à regressão sobre a média quadrática devido ao erro (Tabela 5). $\mathrm{O}$ valor do $\mathrm{F}$ calculado da regressão apresentou-se maior que o $\mathrm{F}$ tabelado e o valor do $\mathrm{F}$ da falta de ajuste mostrou-se menor que o $\mathrm{F}$ tabelado, mostrando que o modelo é preditivo e significativo a nível de confiança de $95 \%$ e que o mesmo não apresenta falta de ajuste dentro da faixa avaliada.

Tabela 5. Efeitos das variáveis avaliadas no rendimento dos ésteres etílicos

\begin{tabular}{lccccc}
\hline Fontes de variação & SQ & GL & MQ & Fcalc. & Ftab. \\
\hline Regressão & 353,98 & 2 & 176,99 & 25,14 & $3,74 *$ \\
Resíduo & 98,54 & 14 & 7,03 & & \\
Falta de ajuste & 97,53 & 12 & 8,12 & 16,19 & $19 *$ \\
Erro puro & 1,00 & 2 & 0,50 & & \\
Total & 452,52 & 16 & & & \\
\hline
\end{tabular}

*nível de 95\% de confiança

O coeficiente de determinação $R^{2}$ foi de 0,78 para a variável ésteres. $\mathrm{O}$ valor $\mathrm{R}^{2}$ é a medida da variação total dos valores observados do rendimento em ésteres sobre a média determinada pelo modelo ajustado, que é freqüentemente expressa em porcentagem. Isto denota que $78 \%$ das variações no rendimento em ésteres são explicadas pelo modelo ajustado. $\mathrm{O}$ coeficiente de correlação $\mathrm{R}=0,89$ explica a relação entre os valores experimentais e os previstos pelo modelo.

De acordo com as áreas de contorno obtidas (Figuras 2 e 3) verifica-se que as variáveis concentração de $\mathrm{NaOH}$ e temperatura $\left({ }^{\circ} \mathrm{C}\right)$, dentro da faixa avaliada, não influenciaram a conversão de triacilgliceróis em ésteres. Entretanto, a concentração de etanol apresentou efeito positivo sobre o rendimento, com melhores resultados quando utilizada entre 35,5 e $44 \%$.

Verifica-se na literatura que a concentração de catalisadores alcalinos utilizados tem variado de 0,4 a 2,0\% (m/m) de óleo. A grande variação nas concentrações utilizadas pode ser atribuída às dife- 
renças existentes nos diversos sistemas reacionais utilizados, tais como tipo e razão molar do álcool utilizado, configuração do reator e matéria-prima . Ferrari et al. ${ }^{11}$ obtiveram $97,5 \%$ de conversão em ésteres etílicos a partir de óleo de soja e etanol anidro sob as seguintes condições operacionais: $3 \mathrm{~L}$ de óleo, $50 \%$ (v/v) de etanol anidro e $15 \mathrm{~g}$ de $\mathrm{NaOH}$, durante $5 \mathrm{~min}$. De acordo com a área de contorno obtida na Figura 2, verifica-se que a concentração de $\mathrm{NaOH}$, dentro da faixa avaliada (0,93 a 1,27\%), não apresentou influência significativa no rendimento em ésteres etílicos, permitindo a escolha da menor concentração de $\mathrm{NaOH}$ testada sem perdas na taxa de conversão em ésteres.

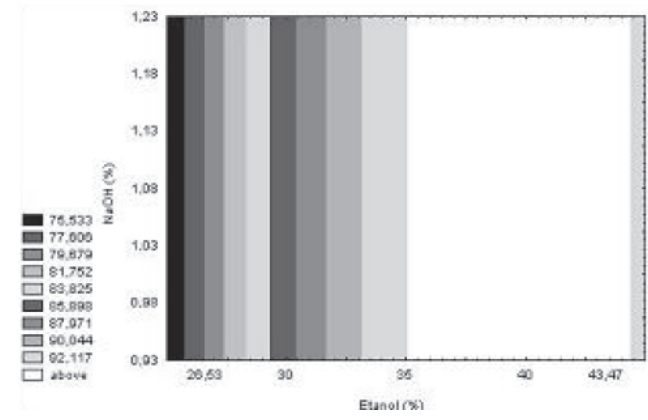

Figura 2. Efeito da concentração de etanol e de $\mathrm{NaOH}$ sobre a conversão de triacilgliceróis em ésteres etílicos

A reação de alcoólise pode ocorrer a diferentes temperaturas, dependendo do óleo utilizado, estando correlacionada ao tempo de reação. A reação de alcoólise tem sido conduzida desde temperatura ambiente até $60{ }^{\circ} \mathrm{C}^{11}$. No entanto, alguns autores sugerem que temperaturas superiores a $60{ }^{\circ} \mathrm{C}$ podem acelerar a saponificação dos triacilgliceróis pelo catalisador alcalino antes da alcoólise completa ${ }^{9}$. De acordo com a área de contorno obtida na Figura 3, verifica-se que a temperatura, dentro da faixa avaliada ( 39 a $65,2^{\circ} \mathrm{C}$ ), não apresentou influência significativa no rendimento em ésteres etílicos, permitindo a escolha da menor temperatura avaliada sem perdas na taxa de conversão em ésteres. A utilização de baixas temperaturas confere maior proteção oxidativa aos ácidos graxos poliinsaturados presentes no óleo de peixe.

Uma das variáveis mais importantes que afetam a conversão de triacilgliceróis em ésteres é a razão molar entre álcool e triacilglicerol. A razão estequiométrica para alcoólise requer três moles de álcool e um de triacilglicerol para a produção de três moles de ésteres e um de glicerol. No entanto, a reação de alcoólise, devido ao seu caráter reversível, requer um excesso de álcool para que haja um deslocamento da reação para a direita. Contudo, um elevado excesso de álcool interfere na separação do glicerol que, devido ao aumento da solubilidade, permanece no meio reacional, ocasionando um deslocamento do equilíbrio da reação para a esquerda e conseqüente redução na conversão em ésteres ${ }^{9}$. Enciner et $a l .{ }^{12}$ avaliaram a influência de diferentes ra-

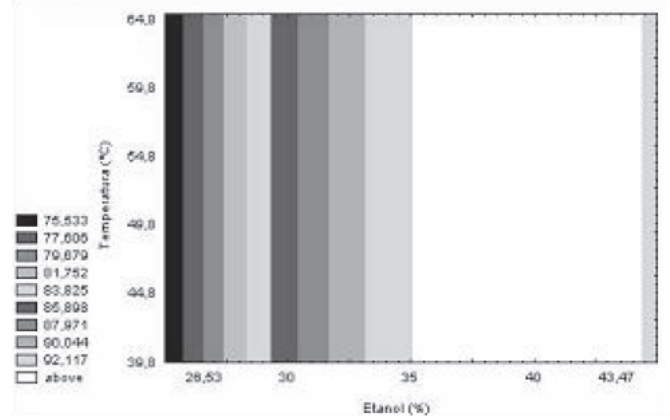

Figura 3. Efeito da concentração de etanol e da temperatura sobre a conversão de triacilgliceróis em ésteres etílicos zões molares, entre 3:1 e 15:1, entre etanol e óleo de cardoon (Cynara cardunculus L.). A reação de alcoólise foi incompleta para razões molares inferiores a 6:1, apresentando melhores resultados de conversão em ésteres entre as razões molares de 9:1 e 12:1. No entanto, com a utilização da razão molar de 15:1 verificou-se uma dificuldade de separação do glicerol do meio reacional e conseqüente decréscimo do rendimento em ésteres. As áreas de contorno obtidas nas Figuras 2 e 3 mostram que a variável etanol apresentou efeito positivo significativo na conversão em ésteres etílicos quando utilizada entre as concentrações de 35 e 43,47\%(v/m), o que corresponde a utilização de razões molares de 5,3:1 e 6,6:1(etanol/óleo), respectivamente. Verifica-se um menor rendimento em ésteres etílicos para razões molares inferiores a 5,3:1 e superiores a 6,6:1.

\section{CONCLUSÃO}

A reação de alcoólise mostrou-se viável para a produção de ésteres etílicos, devido à possibilidade de utilização de temperaturas muito baixas, na faixa de $40{ }^{\circ} \mathrm{C}$, quando comparada ao processo de obtenção convencional de hidrólise de ácidos graxos, no qual se utilizam temperaturas entre $150-280{ }^{\circ} \mathrm{C}$. O processo proposto é uma alternativa tecnológica para óleos ricos em ácidos graxos poliinsaturados, conferindo maior proteção oxidativa aos mesmos.

A reação apresentou taxa de conversão máxima em ésteres etílicos de $95 \%$, dentro da faixa estudada, onde apenas a variável etanol anidro apresentou influência positiva significativa. De acordo com os dados obtidos, sugere-se a utilização de temperatura de $40^{\circ} \mathrm{C}$, concentração de $1 \%$ de $\mathrm{NaOH}$ e $36 \%$ de etanol anidro, sendo esta reação realizada em apenas 5 min sob agitação de 600 rpm. Estas condições são consideradas brandas em termos de agressão térmica ao óleo e levam à possibilidade de obtenção industrial de produtos de alto valor nutricional e melhor protegidos contra a oxidação dos ácidos graxos poliinsaturados.

\section{AGRADECIMENTOS}

À Fapesp pelo apoio financeiro concedido à bolsista (processos 01/08618-6 e 01/12099-4) e à empresa Parmalat pela doação do óleo desodorizado.

\section{REFERÊNCIAS}

1. Grundy, S. M.; Nutrition and Disease Uptade: Heart Desease, Ed. Kritchevsky: D. \& Carroll, K. K., AOCS, Champaign, Illinois, 1994.

2. Stansby, M. E. Em Fish Oils in Nutrition; Stansby, M. E., ed.; Van Nostrand Reinhold: New York, 1990.

3. Rousseau, D.; Marangoni, A. J. Em Food Lipids: Chemistry, Nutrition and Biotechnology; Ed. Akoh, C. C.; Min, D. B., eds.; Marcel Dekker: New York, 1998.

4. Willis, W. M.; Marangoni, A. G. Em ref. 3.

5. Sonntag, N. O. V.; Bailey's Industrial Oil and Fat Products, $4^{\mathrm{a}}$ ed. Ed. Swern, D. Wiley \& Sons: New York, 1982, vol. 2.

6. AOCS - American Oil Chemists Society; Official Methods and Recommended Pratices of the American Oil Chemists' Society, Washington, $5^{\text {th }}$ ed., 2002.

7. Barros Neto, B.; Scarmino, S. I.; Bruns, E. R.; Planejamento e otimização de experimentos, $2^{\mathrm{a}}$ ed., Ed. da Unicamp: Campinas, 1996.

8. Ruiz-Méndez, M. V.; Márquez-Ruiz, G.; Dobarganes, M. C.; Food Chem. 1997, 60, 549 .

9. Meher, L. C.; Sagar, D. V.; Naik, S. N.; www.sciencedirect.com, acessada em Setembro 2005.

10. Erickson, M. D.; Pratical Handbook of Soybean Processing and Utilization, Ed. D. R. Erickson, AOCS, Champaign, Illinois, 1995.

11. Ferrari, R. A.; Oliveira, V. S.; Scabio, A.; Quim. Nova 2005, 28, 19.

12. Enciner, J. M.; Gonzalez, J. F.; Rodrigues, J. J.; Tajedor, A.; Energy Fuels 2002, 16, 443 . 